\title{
Nonprotein-Bound Iron and Plasma Protein Oxidative Stress at Birth
}

\author{
BARBARA MARZOCCHI, SERAFINA PERRONE, PATRIZIA PAFFETTI, BARBARA MAGI, \\ LUCA BINI, CHIARA TANI, MARIANGELA LONGINI, AND GIUSEPPE BUONOCORE
}

Department of Pediatrics, Obstetrics, and Reproductive Medicine [B.Mar, S.P., P.P., C.T., M.L., G.B.], Department of Molecular Biology (B.Mag, L.B.), University of Siena, 53100 Siena, Italy

\section{ABSTRACT}

We previously reported plasma nonprotein-bound iron (NPBI) as a reliable early indicator of intrauterine oxidative stress (OS) and brain injury. We tested the hypothesis that albumin, an NPBI serum carrier, is the major target of NPBIinduced OS. Twenty-four babies were randomly selected from 384 newborns constituting the final cohort of a prospective study undertaken to evaluate the predictive role of NPBI in cord blood for neurodevelopmental outcome. Twelve were selected in the group with lowest NPBI levels $(0-1.16 \mu \mathrm{M})$ and good neurodevelopmental outcome and 12 in the group with highest NPBI levels $(\geq 15.2 \mu \mathrm{M})$ and poor neurodevelopmental outcome. Protein carbonyl groups were identified in cord blood samples by two-dimensional polyacrylamide gel electrophoresis (2D-PAGE) and Western blotting with anti-2,4-dinitrophenyl (DNP) antibodies. Two series of immunoreactive spots, corresponding to serum albumin and $\alpha$-fetoprotein, were found only in the group with highest NPBI levels. We found an association between NPBI and carbonylated proteins in babies with highest NPBI levels. Since NPBI may produce hydroxyl radicals through the Fenton reaction, the major target of OS induced by NPBI is its carrier: albumin. Oxidation of albumin can be expected to decrease plasma antioxidant defenses and increase the likelihood of tissue damage due to OS in the newborns. (Pediatr Res 58: 1295-1299, 2005)

\section{Abbreviations}

2D-PAGE, two-dimensional polyacrylamide gel electrophoresis CG, carbonyl groups

DHP, 1,2-dimethyl-3-hydroxy-4(1H)-pyridone

DNP, 2,4-dinitrophenyl

DNPH, 2,4-dinitrophenyl hydrazine

FR, free radicals

NPBI, nonprotein-bound iron

OS, oxidative stress
Proteins are an important target for oxidative modification; oxidatively modified forms of proteins accumulate during OS induced by free radical (FR) generation. The modification is a consequence of oxidation of amino acid residues on proteins to form protein $\mathrm{CG}$.

CG form during normal aging (1) and in neonates receiving oxygen ventilation (2). Protein CG content is the most widely used marker of oxidative modification of the proteins and the term carbonyl stress has been used to describe excess formation of CG under physiologic and pathologic conditions, such as hypoxia-induced NPBI (3-6).

NPBI indicate a low molecular mass iron form, free of high-affinity binding to transferrin, that seems to occur in plasma, complexed to citrate, lactate, or phosphate or loosely

Received February 2, 2005; accepted April 21, 2005.

Correspondence: Giuseppe Buonocore, M.D., Department of Pediatrics, Obstetrics and Reproductive Medicine, University of Siena, Policlinico "Le Scotte," V.le Bracci 36, 53100 Siena, Italy: e-mail: buonocore@unisi.it

Supported by grants from PAR (Piano di Ateneo per la Ricerca) 2004, University of Siena, Siena, Italy.

DOI: 10.1203/01.pdr.0000183658.17854.28 bound to albumin or other proteins (7). In blood, NPBI causes release of hydroxyl radical $(\mathrm{OH} \cdot)$ by superoxide and hydrogen peroxide, possibly via iron-oxygen complexes (8). $\mathrm{OH} \cdot$ is an extremely powerful oxidizing species. It attacks all classes of biologic macromolecules depolymerizing polysaccharides, breaking DNA strands, inactivating enzymes, and peroxidating lipids (9-11). NPBI is released from hemoglobin when erythrocytes are challenged by an oxidative stress $(12,13)$. The newborn is very susceptible to NPBI-induced oxidative stress (14). Recently we reported that NPBI released by erythrocytes in vitro is much higher with hypoxic erythrocytes from newborns compared with that from adults (6). Asphyxia could affect iron metabolism and lead to a significant increase in NPBI and lipid peroxidation in plasma of newborns with hypoxic ischemic encephalopathy, indicating that iron delocalization induced by asphyxia plays a role in the brain injury of asphyxiated infants (15).

We demonstrated that plasma NPBI is a reliable early indicator of intrauterine OS and brain injury (5). The aim of present study was to detect protein oxidant stress in the pres- 
ence of NPBI in plasma by identifying carbonylated proteins. There are several methods of measuring carbonylated protein; in all of them, 2,4-dinitrophenyl hydrazine (DNPH) is allowed to react with protein carbonyls to form the corresponding hydrazone, which can be analyzed immunochemically. Oxidation is measured by evaluating overall protein carbonylation but not oxidation of individual plasma proteins. This evaluation is useful for establishing specific pathways of OS in vivo and for determining potential functional consequences of exposure to FR. High-resolution two-dimensional electrophoretic separation of plasma proteins combined with Western blot analysis was recently suggested as an appropriate technique (16). This method made it possible to evaluate the simultaneous presence of all CG in all plasma proteins. We tested the hypothesis that albumin, the carrier of NPBI in plasma, is the major target of NPBI-induced OS.

\section{MATERIALS AND METHODS}

Patients. Twenty-four babies were selected from 384 newborns constituting the final cohort of a prospective study undertaken to evaluate the predictive role of NPBI in cord blood for neurodevelopmental outcome (5). In that study, 400 of the 2902 babies born in the Neonatology Division, Department of Pediatrics, Obstetrics and Reproductive Medicine, University of Siena (Italy) in the period June 1, 1997 to May 31, 2000 were enrolled according to a random algorithm using the Minitab statistical software package (Mintab Inc., State College, PA). The number lost to follow-up during the study period was 16. The final cohort consisted of 384 newborns with gestational ages from 24 to 42 weeks: $225>36$ weeks, $69<32$ weeks, and birth weight $<1500 \mathrm{~g}$ (range, 490-5300 g).

Neonatal neurodevelopmental examinations were performed at a mean postmenstrual age of 38 weeks according to the criteria of Allen and Capute (17). Follow-up visits were scheduled at age 1, 2, 4, 12, and 24 months. Physical and neurologic examinations were performed by the same neonatal neurologist. Motor development was assessed in the areas of muscle tone, primitive reflexes, automatic reactions, and head and trunk tone. The evaluation included quantitative changes and quality of performance in developmental patterns and milestones. Three to four transfontanellar cranial ultrasound examinations were performed within the first $6-8$ months of follow-up by one experienced neonatologist blind to outcome. Hearing tests included free-field behavioral audiometry and tympanography and were carried out by an audiologist. Children were also seen for formal assessment by a pediatric ophthalmologist. Formal developmental testing was performed with the Bayley Scales of Infant Development, an age-adjusted standardized test that compares motor development and cognitive skills to established nomograms with a psychomotor developmental index and a mental developmental index (18).

Fifty-one of the 384 babies (13.3\%) showed persistent abnormal neurodevelopmental status at 24 months. This percentage was similar to that observed in whole population of newborns $(n=2902)$ in the study period.
Twelve babies from the group with the lowest NPBI levels and good neurodevelopmental outcome $(n=333$; NPBI $0-1.16 \mu \mathrm{M})$ and 12 from the group with the highest NPBI levels and poor neurodevelopmental outcome ( $n$ $=51 ; \mathrm{NPBI} \geq 15.2 \mu \mathrm{M}$ ) were randomly selected to study protein CG formation under conditions of negligible or severe risk of OS independently of gestational age or birth weight. Indeed despite the high vulnerability of the brain of very low birth weight infants and the higher rate of the motor deficit associated with immaturity and low birth weight, a recent report on the population register of cerebral palsy showed that half of the children weighed more than $2500 \mathrm{~g}$ at birth. Clinical characteristics of newborns are listed in Table 1.

The study was approved by the Human Ethics Committee of the Medical Faculty, University of Siena. Informed written parental consent was obtained before enrollment of each infant.

Methods. All evaluations were performed in cord blood at birth. Cord blood samples were immediately centrifuged at $1200 \times g$ at $4^{\circ} \mathrm{C}$ for 20 minutes. The plasma was stored at $-80^{\circ} \mathrm{C}$ until analysis. Plasma concentrations of NPBI were measured by high-performance liquid chromatography using the method described by Kime et al. (19), as previously reported (5).

NPBI was determined with the system operating at a pressure of 90-95 bar and a flow rate of $0.75 \mathrm{~mL} / \mathrm{min}$. Detection was carried out subtracting the absorption at $620 \mathrm{~nm}$ from that at $450 \mathrm{~nm}$.

The method is based on preferential chelation of NPBI by a large excess of the low-affinity ligand disodium nitrilotriacetic acid. Disodium nitrilotriacetic acid captures all iron bound to low molecular weight proteins and nonspecifically bound to serum proteins. It does not remove iron bound to transferrin or ferritin. To separate NPBI, a two-step filtration procedure was used: 1) filtration through a 100-kD MWCO Vecta-Spin Micro-Whatman ultracentrifuge filter; 2) filtration through a 20-kD MWCO Vecta Spin Micro-Whatman ultracentrifuge filter at RCF 16.1 and $4{ }^{\circ} \mathrm{C}$.

The filtrate was injected directly into an isocratic reverse-phase liquid chromatography system using precolumn derivatization with the high-affinity iron ligand DHP, which forms a colored complex with $\mathrm{Fe}^{3+}$ that absorbs at 450 $\mathrm{nm}$. All glassware and plastic ware was treated to minimize iron contamination.

The analytic system detected iron as ferric nitrate standard down to a concentration of $0.01 \mu \mathrm{M}$. The DHP-Fe complex eluted with a retention time of about 2.6 minutes. The standard curve for the DHP-Fe complex was linear between 0.01 and $400 \mu \mathrm{M}$ in water as well as in plasma. Detection limit was $0.01 \mu \mathrm{M}$.

2D-PAGE was carried out with $6-\mu \mathrm{L}$ aliquots of plasma denatured in rehydration buffer (8 M urea, 4\% 3-(3-cholamidopropyl)dimethyl-ammonio)1-propanesulfonic acid, $65 \mathrm{mM}$ dithioerythritol, $0.8 \%$ carrier ampholytes (Resolyte 4-8; BDH, Poole U.K.) and a trace amount of bromophenol blue). The same amount of protein $(60 \mu \mathrm{g})$ was used for each test. For 2D-PAGE, an Immobiline-polyacrylamide system was used (20). Isoelectric focusing (first dimension) was carried out on a precast Immobiline dry strip, with $\mathrm{pH}$ gradient from pH 3 to 10 (nonlinear 18-cm IPG strips; Amersham Pharmacia Biotechnology, Uppsala, Sweden). After isoelectric focusing, the strips were briefly rinsed with water and incubated at room temperature in 5\% trifluoroacetic acid containing $10 \mathrm{mM}$ DNPH for 20 minutes. The DNPH-treated strips were washed twice for 5 minutes with a solution containing $8 \mathrm{M}$ urea, $20 \%$ (vol/vol) glycerol, $1 \%$ (wt/vol) SDS, and $150 \mathrm{mM}$ Tris- $\mathrm{HCl}(\mathrm{pH} \mathrm{6.8)}$ ). They were then equilibrated in a solution containing $50 \mathrm{mM}$ Tris- $\mathrm{HCl}(\mathrm{pH} 6.8), 6 \mathrm{M}$ urea, $30 \%$

Table 1. Clinical characteristics of the patients at birth

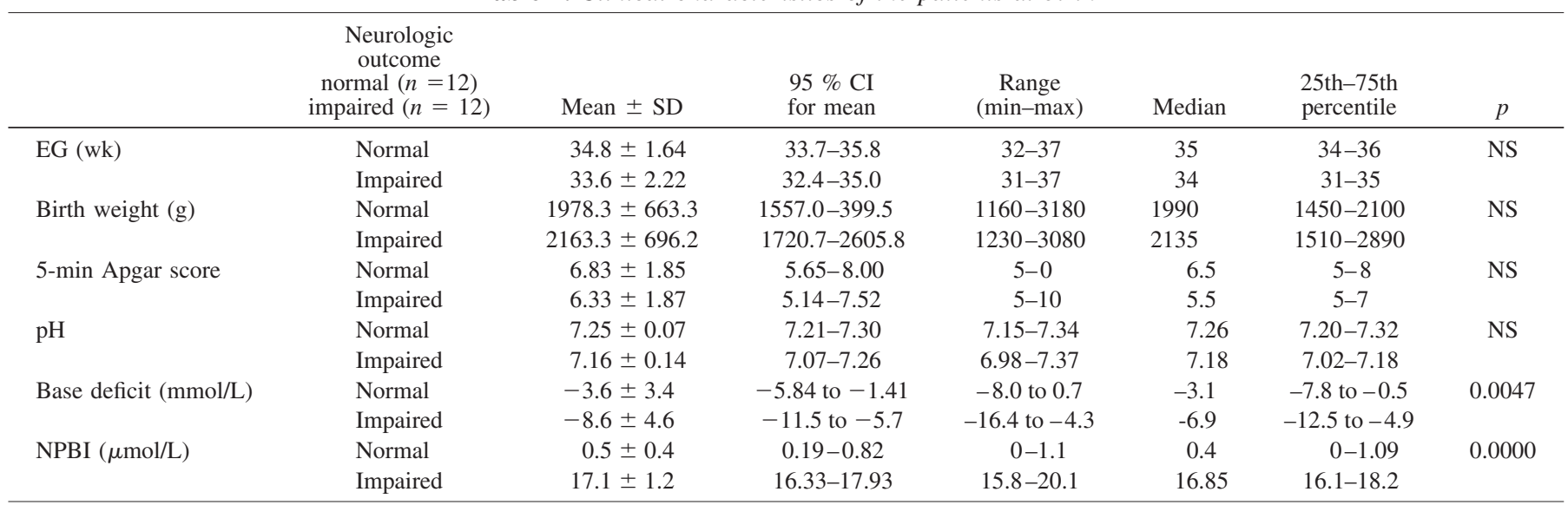


$\mathrm{vol} / \mathrm{vol}$ glycerol, $2 \% \mathrm{wt} / \mathrm{vol}$ SDS and 2\% wt/vol DTE for 12 minutes. Then -SH groups were blocked with a solution containing $50 \mathrm{mM}$ Tris- $\mathrm{HCl}(\mathrm{pH} 6.8), 6$ $\mathrm{M}$ urea, $30 \% \mathrm{vol} / \mathrm{vol}$ glycerol, $2 \% \mathrm{wt} / \mathrm{vol} \mathrm{SDS}, 2.5 \% \mathrm{wt} / \mathrm{vol}$ iodoacetamide, and a trace of bromophenol blue for 5 minutes.

The second dimension was performed on 9 to 16 polyacrylamide linear gradient gels that were stained with ammoniacal silver nitrate as already described (21). Proteins were then electroblotted into nitrocellulose membrane (22) and their transfer checked with Coomassie staining of the gels after blotting. Before immunodetection, the membranes were stained in $0.2 \%$ $(\mathrm{wt} / \mathrm{vol})$ Ponceau $\mathrm{S}$ in 3\% (wt/vol) trichloroacetic acid for 3 minutes. Spot position was marked to facilitate computer-aided matching of the silver-stained gels.

The working dilution for the polyclonal antibody against dinitrophenyl (anti-DNP) (SIGMA) was 1:10.000. The immunoreactive spots were detected using peroxidase-conjugated anti-rabbit IgG or whole molecule Ig (working dilution 1:7.000) (SIGMA). A chemiluminescence detection system (Amersham Pharmacia Biotech International, Little Chalfont, U.K.) was used according to the manufacturer's instructions. Immunoreactive spots and nonimmunoreactive spots were identified by matching with two-dimensional reference maps of human plasma $(23,24)$ and fetal serum $(25)$.

Electrophoretic images were digitized using a computing densitometer $(4000 \times 5000$ pixels; 12 bits/pixel $)$ by Molecular Dynamics Amersham Biosciences (Uppsala, Sweden) and analyzed on a SUN SPARC station 10 with Melanie II (Bio-Rad Laboratories, Milan, Italy) software, which automatically detects and compares protein spots on digitized two-dimensional images. Gel matching is a key operation in two-dimensional image analysis involving comparison of gel images for "pairs" of spots representing the same protein in both gels. The matching program of Melanie II identifies proteins by comparison with 2D reference maps (26). Protein identification was achieved on the basis of close matching of electrophoretic coordinates ( $\mathrm{pI}$ and $\mathrm{M}_{\mathrm{r}}$ directly related to amino acid composition) between spots in our map and spots already identified on a two-dimensional reference map of human plasma available in the Expasy World Wide Web molecular biology server of Geneva University Hospital and the University of Geneva (http://www.expasy.ch).

Statistical analysis. Statistical analysis was done with the SPSS-PC +4 (SPSS Inc. Chicago, IL) statistical package. The two-tailed Student $t$ test for unpaired data were used to compare gestational age and birth weight between groups.

\section{RESULTS}

No statistically significant differences in gestational age or birth weight were observed between babies in the group with the lowest NPBI levels and good neurodevelopmental outcome and those in the group with the highest NPBI levels and poor neurodevelopmental outcome. No differences were also found in plasma albumin and $\alpha$-fetoprotein concentrations between the two groups. Figure 1 shows a typical two-dimensional silver-stained electrophoretogram of fetal cord blood plasma. No reliable quantitative differences were detected by comparison of electrophoretograms of hypoxic and normoxic babies. Figures 2 and 3 show representative Western blots for detection of CG. All 12 samples of the group with the lowest NPBI levels and good neurodevelopmental outcome (Fig. 2) showed four carbonylated series of immunoreactive spots, corresponding $\alpha_{1}$-antitrypsin, serotransferrin, IgG heavy chain, and fibrinogen $\beta$ chain. All 12 samples of the group with the highest NPBI levels and poor neurodevelopmental outcome (Fig. 3) showed six series of immunoreactive spots. Of these, four series corresponded to $\alpha_{1}$-antitrypsin, serotransferrin, $\operatorname{IgG}$ heavy chain, and fibrinogen $\beta$ chain as observed in the group with good neurodevelopmental outcome, and two other carbonylated series, corresponding to albumin and $\alpha$-fetoprotein, were found only in the group with the highest NPBI levels. No other detectable differences were observed between samples in either group.

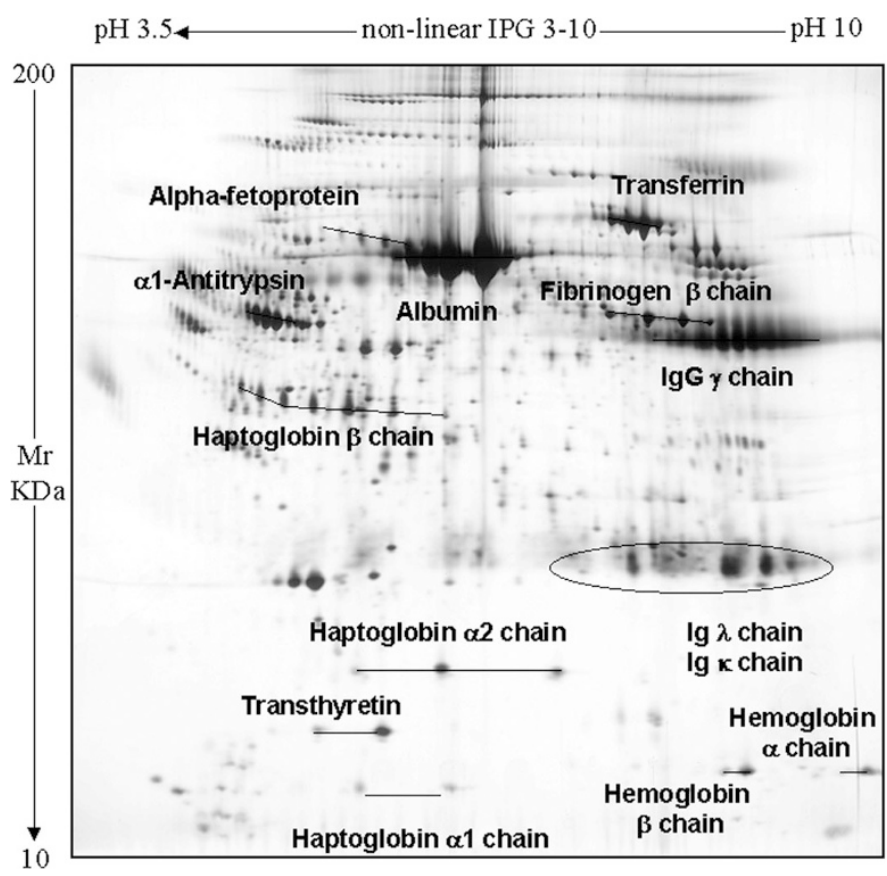

Figure 1. Typical two-dimensional silver stained electrophoretogram of fetal cord blood serum. Some of the proteins, identified by matching with reference maps of human fetal plasma, are indicated.

$\mathrm{pH} 3.5 \longleftarrow$ non-linear IPG 3-10 $\mathrm{pH} 10$

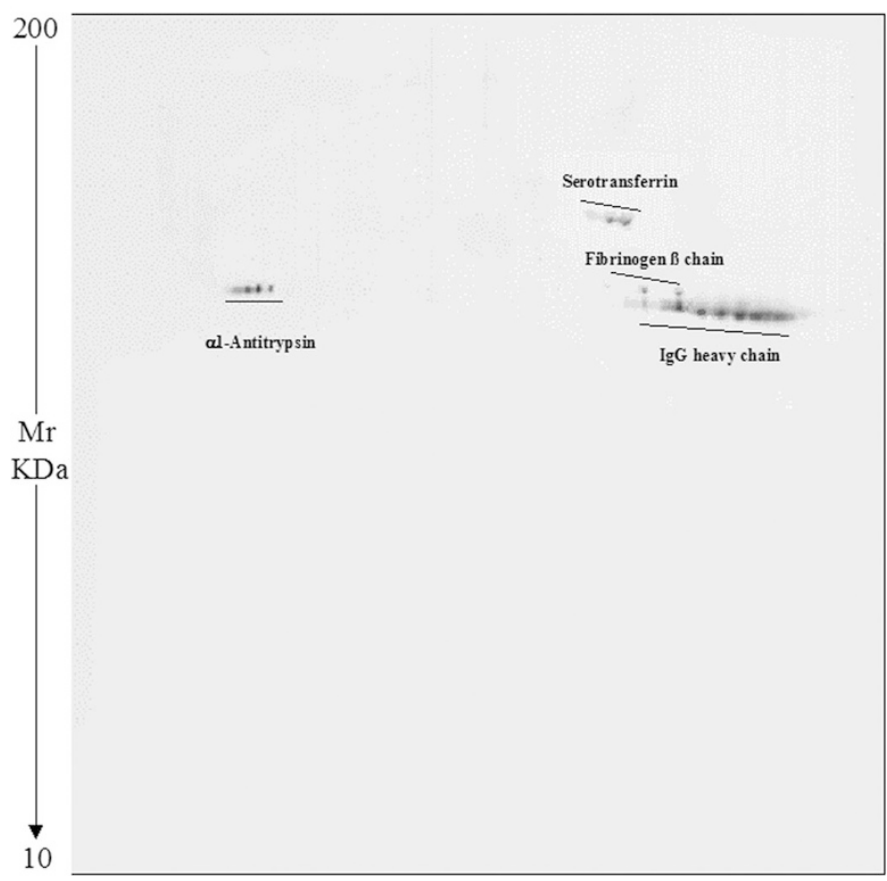

Figure 2. Representative two-dimensional Western-blot profile showing proteins immunoreactive with anti-DNP antibodies in cord blood plasma from neonates having good neurodevelopmental outcome (NPBI 0-1.16 $\mu \mathrm{M}$ ).

\section{DISCUSSION}

The results showed that only babies with the high concentrations of NPBI in plasma have CG on albumin and also on $\alpha$-fetoprotein, a serum protein with a similar amino acid sequence to albumin. No CG were detectable on albumin and $\alpha$-fetoprotein of babies with NPBI concentrations in the range $0-1.16 \mu \mathrm{M}$. 
$\mathrm{pH} 3.5$ non-linear IPG 3-10 $\mathrm{pH} 10$

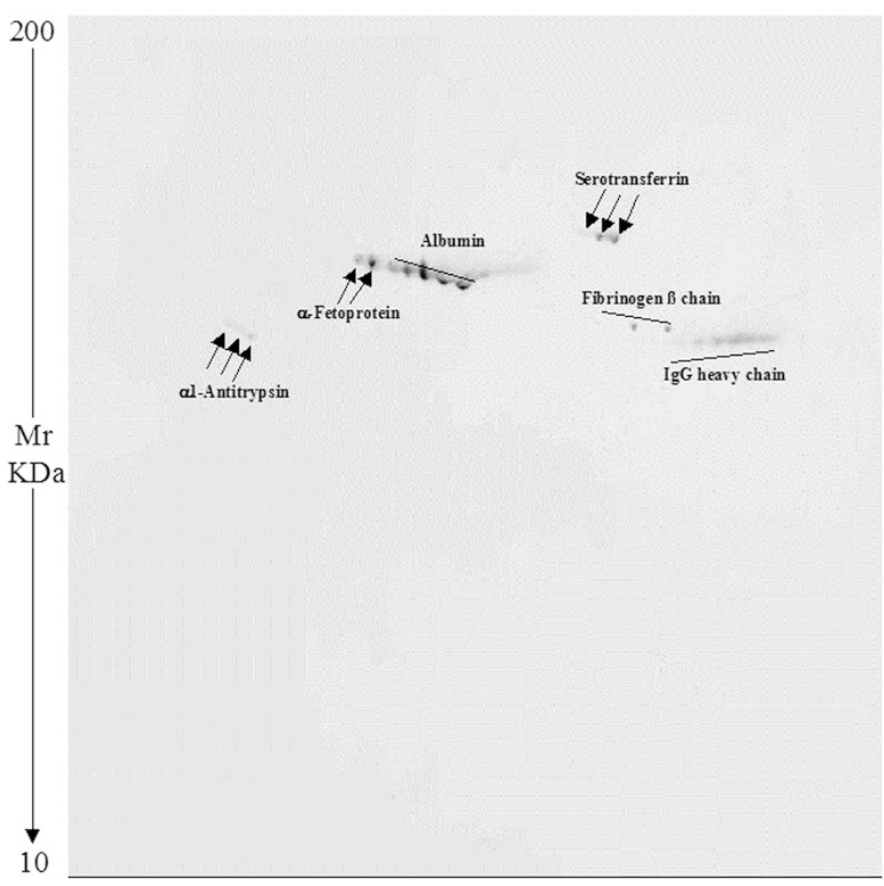

Figure 3. Representative two-dimensional Western-blot profile showing proteins immunoreactive with anti-DNP antibodies in cord blood plasma from neonates having poor neurodevelopmental outcome (NPBI $\geq 15.2 \mu \mathrm{M}$ ).

Proteins are the main target of oxidation in the plasma (27). Protein-FR interactions may have considerable significance in vivo, since $10-50 \%$ of all antioxidant potential of human plasma challenged with peroxyl radicals seems to be due to proteins (28). Altered protein molecules such as protein peroxides and protein-bound reducing moieties can act as "traps" for chemical energy released by FR and initiate further chain reactions involving radicals, aggravating the damage $(1,29)$. This follows from the fact that hydrogen peroxide and alkylperoxides, the most common end products of most FR generating systems, are converted to hydroxyl radicals $(\mathrm{OH} \cdot)$ or alkoxyl radicals (RO.) in the presence of the transition metals $\mathrm{Fe}$ (II) and $\mathrm{Cu}$ (I). Catalytic iron may be derived from ferritin, although transferrin, hemoglobin, myoglobin, lactoferrin, and cytochromes are other possible sources. During hypoxia and reoxygenation, iron is mobilized from storage sites and converted from a ferrozine-undetectable to a ferrozine-detectable form. Not only is the quantity of ferrozine-detectable iron increased by hypoxia, but a greater fraction of it is also released into the extracellular space during hypoxia and reoxygenation. Whatever the origin, iron release and FR generation expose newborns with poorly developed antioxidant systems to oxidative damage. We previously demonstrated that preterm babies had higher concentrations of NPBI and lower antioxidant responses than term babies (13,30,31). A strong correlation exists between NPBI concentration and gestational age at birth. We also found high OS to lipids and proteins in cord blood of preterm neonates and in blood samples obtained at 1 week $(9,32)$.

In the present study, we used high-resolution 2D-PAGE separation of plasma proteins and Western blotting with anti-
DNP IgG to identify all proteins in plasma and all proteins carrying CG. Derivatization of CG with DNPH and subsequent anti-DNP immunoblotting is a very sensitive and specific test, reported (33) to detect carbonyl concentrations as low as 1 pmol. Therefore, without considering carbonylated proteins in both groups, the presence of immunoreactivity only for albumin, means that no other protein is carbonylated to a carbonyl concentration of 1 pmol.

The finding of $\alpha$-fetoprotein carbonylation further supports this hypothesis: $\alpha$-fetoprotein is a fetal serum protein that progressively disappears as gestational age increases. It has a function similar to serum albumin and a similar sequence, with three albumin domains.

To our knowledge this is the first report showing albumin carbonylation in newborns with the highest NPBI levels and poor neurodevelopmental outcome. Since NPBI may produce hydroxyl radicals via the Fenton reaction, the major target of OS induced by NPBI is its carrier, albumin.

Living organisms are constantly exposed to reactive oxygen species that can damage proteins. This means that several carbonylated proteins are normally present under physiologic conditions (34). In plasma, free thiol and sulfhydryl groups are quantitatively the most important scavengers of virtually all kinds of oxidants and are known to be largely located on albumin and $\alpha$-fetoprotein (35). We previously demonstrated decreased availability of sulfhydryl groups in red blood cells of newborns, which contributed to the susceptibility of these cells to the effect of oxidative agents (36). Among the various plasma factors, free thiols and sulfhydryl groups located on albumin and $\alpha$-fetoprotein are the main contributors to plasma redox power; this may be an explanation for increased susceptibility to oxidation in a metal-dependent oxidizing system.

These data are in line with a recent report (37) in which Western blot was used to demonstrate that albumin was the main plasma protein modified by OS in patients with chronic renal failure. Since albumin is a major extracellular antioxidant, its susceptibility to oxidation suggests that albumin, as carrier of NPBI in plasma, is the major target of NPBI-induced OS. Oxidation of albumin can therefore be expected to decrease plasma antioxidant defenses and increase the likelihood of tissue damage due to OS in the newborn. This finding is extremely relevant to clinical practice suggesting a role for NPBI chelators in decreasing neonatal oxidative stress (38).

\section{REFERENCES}

1. Stadtman ER, Levine RL 2000 Protein oxidation. Ann N Y Acad Sci 899:191-208

2. Gladstone IM Jr, Levine RL 1994 Oxidation of proteins in neonatal lungs. Pediatrics 93:764-768

3. Miyata T, van Ypersele de Strihou C, Kurokawa K, Baynes JW 1999 Alterations in nonenzymatic biochemistry in uremia: origin and significance of "carbonyl stress" in long-term uremic complications. Kidney Int 55:389-399

4. Himmelfarb J, McMonagle E, McMenamin E 2000 Plasma protein thiol oxidation and carbonyl formation in chronic renal failure. Kidney Int 58:2571-2578

5. Buonocore G, Perrone S, Longini M, Paffetti P, Vezzosi P, Gatti MG, Bracci R 2003 Non protein bound iron as early predictive marker of neonatal brain damage. Brain 126:1224-1230

6. Ciccoli L, Rossi V, Leoncini S, Signorini C, Blanco-Garcia J, Aldinucci C, Buonocore G, Comporti M 2004 Iron release, superoxide production and binding of autologous $\mathrm{IgG}$ to band 3 dimers in newborn and adult erythrocytes exposed to hypoxia and hypoxia-reoxygenation. Biochim Biophys Acta 1672:203-213

7. Grootveld M, Bell JD, Halliwell B, Aruoma OI, Bomford A, Sadler PJ 1989 Non-transferrin-bound iron in plasma or serum from patients with idiopathic hemo- 
chromatosis. Characterization by high performance liquid chromatography and nuclear magnetic resonance spectroscopy. J Biol Chem 264:4417-4422

8. Schafer FQ, Qian SY, Buettner GR 2000 Iron and free radical oxidations in cell membranes. Cell Mol Biol 46:657-662

9. Buonocore G, Perrone S, Longini M, Paffetti P, Marzocchi B, Vezzosi P, Bracci R 2002 Oxidative stress in preterm neonates at birth and on the seventh day of life. Pediatr Res 52:46-49

10. Halliwell B, Gutteridge JM 1990 Role of free radicals and catalytic metal ions in human disease: an overview. Methods Enzymol 186:1-85

11. Halliwell B, Gutteridge JM 1992 Biologically relevant metal ion-dependent hydroxy radical generation. An update. FEBS Lett 307:108-112

12. Ferrali M, Signorini C, Ciccoli L, Comporti M 1992 Iron release and membrane damage in erythrocytes exposed to oxidizing agents, phenylhydrazine, divicine and isouramil. Biochem J 285:295-301

13. Buonocore G, Zani S, Perrone S, Caciotti B, Bracci R 1998 Intraerythrocyte nonprotein-bound iron and plasma malondialdehyde in the hypoxic newborn. Free Radic Biol Med 25:766-770

14. Bracci R, Buonocore G 1998 The antioxidant status of erythrocytes in preterm and term infants. Semin Neonatol 3:191-197

15. Yu T, Kui LQ, Ming QZ 2003 Effect of asphyxia on non-protein-bound iron and lipid peroxidation in newborn infants. Dev Med Child Neurol 45:24-27

16. Reinheckel T, Körn S, Möhring S, Augustin W, Halangk W, Schild L 2000 Adaptation of protein carbonyl detection to the requirements of proteome analysis demonstrated for hypoxia/reoxygenation in isolated rat liver mitochondria Arch Biochem Biophys 376:59-65

17. Allen MC, Capute AJ 1989 Neonatal neurodevelopmental examination as a predictor of neuromotor outcome in premature infants. Pediatrics 83:498-506

18. Bayley N 1969 Bayley Scales of Infant Development. The Psychological Corp, New York,

19. Kime R, Gibson A, Yong W, Hider R, Powers H 1996 Chromatographic method fo the determination of non-transferrin-bound iron suitable for use on the plasma and bronchoalveolar lavage fluid of preterm babies. Clin Sci 91:633-638

20. Bjellqvist B, Pasquali C, Ravier F, Sanchez JC, Hochstrasser DF 1993 A nonlinear wide-range immobilized $\mathrm{pH}$ gradient for two-dimensional electrophoresis and its definition in a relevant $\mathrm{pH}$ scale. Electrophoresis. 14:1357-1365

21. Hochstrasser DF, Patchornik A, Merril CR 1988 Development of polyacrylamide gel that improve the separation of proteins and their detection by silverstaining Ana Biochem 173:412-423

22. Towbin H, Staehelin T, Gordon J 1979 Electrophoretic transfer of proteins from polyacrylamide gels to nitrocellulose sheets: procedure and some applications. Proc Natl Acad Sci U S A 76:4350-4354

23. Hughes GJ, Frutiger S, Paquet N, Ravier F, Pasquali C, Sanchez JC, James R, Tisso JD, Bjellqvist B, Hochstrasser DF 1992 Plasma protein map: an update by microsequencing. Electrophoresis 13:707-714
24. Golaz O, Hughes GJ, Frutiger S, Paquet N, Bairoch A, Pasquali C, Sanchez JC, Tissot JD, Appel RD, Walzer C, et al 1993 Plasma and red blood cell protein maps: update. Electrophoresis 14:1223-1231

25. Tissot JD, Hohlfeld P, Forestier F, Tolsa JF, Hochstrasser DF, Calame A, Plouvier E, Bossart H, Schneider P 1993 Plasma/serum protein patterns in human fetuses and infants: a study by high-resolution two-dimensional polyacrylamide gel electrophoresis. Appl Theor Electrophor 3:183-190

26. Appel RD, Palagi PM, Walther D, Vargas JR, Sanchez JC, Ravier F, Pasquali C, Hochstrasser DF 1997 Melanie II-a third-generation software package for analysis of two-dimensional electrophoresis images: I. Features and user interface. Electrophoresis $18: 2724-2734$

27. Dean RT, Fu S, Stocker R, Davies MJ 1997 Biochemistry and pathology of radical-mediated protein oxidation. Biochem $\mathrm{J}$ 324:1-18

28. Wayner DD, Burton GW, Ingold KU, Barclay LR, Locke SJ 1987 The relative contributions of vitamin E, urate, ascorbate and proteins to the total peroxyl radicaltrapping antioxidant activity of human blood plasma. Biochim Biophys Acta 924:408-419

29. Simpson JA, Gieseg SP, Dean RT 1993 Free radical and enzymatic mechanisms for the generation of protein bound reducing moieties. Biochim Biophys Acta 1156:190 196

30. Frosali S, Di Simplicio P, Perrone S, Di Giuseppe D, Longini M, Tanganelli D, Buonocore G 2004 Glutathione recycling and antioxidant enzyme activities in erythrocytes of term and preterm newborns at birth. Biol Neonate 85:188-194

31. Halliwell B, Gutteridge JM 1990 The antioxidants of human extracellular fluids. Arch Biochem Biophys 280:1-8

32. Buonocore G, Perrone S, Longini M, Terzuoli L, Bracci R 2000 Total hydroperoxide and advanced oxidation protein products in preterm hypoxic babies. Pediatr Res 47:221-224

33. Nakamura A, Goto S 1996 Analysis of protein carbonyls with 2,4-dinitrophenyl hydrazine and its antibodies by immunoblot in two-dimensional gel electrophoresis J Biochem 119:768-774

34. Stadtman ER, Levine RL 2000 Protein oxidation. Ann N Y Acad Sci 899:191-208

35. Soriani M, Pietraforte D, Minetti M 1994 Antioxidant potential of anaerobic human plasma: role of serum albumin and thiols as scavengers of carbon radicals. Arch Biochem Biophys 312:180-188

36. Bracci R, Martini G, Buonocore G, Talluri B, Berni S, Ottaviani MF, Picchi MP, Casini A 1988 Changes in erythrocyte properties during the first hours of life: electron spin resonance of reacting sulfhydryl groups. Pediatr Res 24:391-395

37. Himmelfarb J, McMonagle E 2001 Albumin is the major plasma protein target of oxidant stress in uremia. Kidney Int 60:358-363

38. Peeters-Scholte C, Braun K, Koster J, Kops N, Blomgren K, Buonocore G, van Buul-Offers S, Hagberg H, Nicolay K, van Bel F, Groenendaal F 2003 Effects of allopurinol and deferoxamine on reperfusion injury of the brain in newborn piglets after neonatal hypoxia-ischemia. Pediatr Res 54:516-522 